\title{
Trajeto Dadivoso do Teatro da Cura: Uma Encenação- Quiasma em atos de agradecer, transformar e dádiva
}

\author{
IVONE MARIA XAVIER DE AMORIM ALMEIDA
}

WLADILENE LIMA

Ivone Maria Xavier de Amorim Almeida é Doutora em História Social pela Pontifícia Universidade Católica de São Paulo (2010) e Mestre em Antropologia Social pela Universidade Federal do Pará (1998).É professora Adjunta da Universidade federal do Pará (UFPA), lotada no Instituto de Ciências e Artes (ICA), vinculada à Escola de Teatro e Dança (ETDUFPA). Compõe o quadro de professores do Programa de Pós-graduação em Artes em Rede Nacional (UFPA) e do Programa de Mestrado Acadêmico em Artes do PPGARTES-UFPA. Estabelece diálogos entre Artes e as Epistemologias do XIX,XX e XXI. Desenvolve pesquisa sobre Narrativas Míticas e suas relações com os elementais (terra, água, ar e fogo) em comunidades continentais e insulares da Amazônia Paraense. Tem experiência na área da Antropologia do Imaginário e Sociologia do Teatro. É pesquisadora-colaboradora nos projetos TAMBOR e AUTO DO CÍRIO (PPGARTES-ETDUFPA). Atua especialmente nos temas:Encantarias, Festas Populares, Religiosidade, Corpo, Memória.

Wladilene Lima é Artista-pesquisadora com mestrado e doutorado em Artes Cênicas pela UFBA e estágio de Pós-doutoramento no Programa Doutoral em Estudos Culturais das Universidades de Aveiro e Minho, Portugal. Na UFPA, trabalha no Programa de Pós-Graduação em Arte e na Escola de Teatro e Dança. Atua como atriz, diretora e cenógrafa na categoria teatral da cidade de Belém do Pará, especificamente, nos seguintes coletivos: Grupo Cuíra do Pará e Coletivas Xoxós. É a gestora artística do Poética Criatura - Laboratório de Teatro de Porão, novo espaço de criação e resistência artivista, localizado no centro histórico da cidade de Belém. 


\section{- RESUMO}

O presente artigo tem como objeto investigativo um projeto experimental que se reconhece como Teatro da Cura, especificamente, o movimento criador da encenação-quiasma intitulada, Oh de casa! Posso entrar para cuidar? produzido, dirigido e encenado pelo grupo de teatro Coletivas Xoxós de Belém do Pará. A estrutura desta encenação-quiasma compreende dois cardápios de encenação: agradecimento e transformação. A casa-teatro solicitante escolhe o cardápio que deseja receber. No corpo do texto, os atos de agradecimento e transformação são analisados como fatos sócio-antropo-mágicos sob a luz da Teoria da Dádiva proposta por Marcel Mauss; seus procedimentos poéticos in process convocam os cuidados de si e da vida sob a régia das artistas da cena. A compreensão do Teatro da Cura aqui proposta encontra amparo nas reflexões teóricas sobre teatro defendidas por Eugênio Barba, Nicola Savarese e Peter Brook.

\section{- PALAVRAS-CAVE}

Encenação-Quiasma, corpo-casa, dádiva

\section{ABSTRACT}

The present article has as investigative object an experimental project that it recognizes as Theater of the Cure, specifically, the creative movement of the intitled stage-quiasma, Oh of house! Can I enter to take care of? produced, directed and staged for the Collective group of theater Xoxós de Belém of Pará. The structure of this stage-quiasma understands two cardápios of stage: gratefulness and transformation. The solicitant house-theater chooses the cardápio that it desires to receive. In the body of the text, the acts of gratefulness and transformation are analyzed as facts partner-antropo-magicians under the light of the Theory of the Gift proposal for Marcel Mauss; its poetical procedures in process convoke the cares of itself and the life under the regal one of the artists of the scene, Collective the Xoxós. The understanding of the Theater of the Cure proposal finds support in the theoretical reflections here on theater defended by Eugênio Beard, Nicola Savarese and Peter Brook.

\section{KEYWORDS}

Stage. Body-House. Gift

Sentimento é a língua que o coração usa quando precisa mandar algum recado

Adriana Falcão (escritora brasileira)

\section{Primeiras palavras}

Um cântico anuncia a chegada do Teatro de Cura a mais uma casa das ruas da cidade de Belém do Pará, Amazônia Oriental. Começa o espetáculo! Quando as portas se abrem, quem invade a casa é o elemento éter - o plasma; o bio-plasma. A atriz-narradora que representa esse elemento entra para saudar e limpar o 
ambiente, seus moradores e visitantes. Em seguida, a casa recebe outros quatro elementos: a terra, a água, o fogo e o ar.

O corpo-casa é agora uma metáfora do universo em movimento de criação. Instaladas no centro daquele microcosmo, as atrizes-narradoras, generosamente, compartilham histórias de vida, narrativas ficcionais, poesias, pensamentos, orações e toda uma minúcia de gestos em diálogo com múltiplas sensibilidades religiosas, como práticas do dar, receber e retribuir energias, acionadas e compartilhadas, naquele lócus íntimo, a casa dos outros, na perspectiva de cuidar de si e de cada um, de todo o coletivo ali presente, no desejo intencional de cura. Todo este ato poético é aqui compreendido como encenação-quiasma.

O teatro que se presentifica na casa de cada um, com e para o olhar e coração do outro se expande para além do teatro ordinário, se quer teatro do extraordinário; se quer teatro dadivoso.

\title{
A Noção da Dádiva
}

É inegável a contribuição de Marcel Mauss para a Sociologia e Antropologia. A arte, e mais particularmente, as artes da cena, também hoje dialogam com esse autor, principalmente no que tange aos estudos do corpo. Na contemporaneidade é considerado o principal sistematizador da Teoria da Dádiva "que vem sendo resgatada como um modelo interpretativo de grande atualidade para se pensar os fundamentos da solidariedade e da aliança nas sociedades contemporâneas" (MARTIN, 2005,p.2).

As inquietações provocadoras em Mauss para escrever o Ensaio sobre a Dádiva giram em torno de duas perguntas complementares: por que as dádivas de presentes devem ser obrigatoriamente devolvidas? E por que existe essa universalidade da retribuição?

Foi no Ensaio sobre a dádiva que Mauss introduziu o Fato Social Total como categoria sociológica que possibilita o revelar sobre a realidade social, posto que "o social só é real quando integrado em sistema ${ }^{1}$. No dizer de Mauss,

\begin{abstract}
Nesses fenômenos sociais totais, como nos propomos chamá-los, exprimem-se, ao mesmo tempo e de uma só vez, toda espécie de instituições: religiosas, jurídicas e morais - estas políticas e familiais ao mesmo tempo; econômicas - supondo formas particulares de produção e de consumo, ou antes, de prestação e de distribuição, sem contar os fenômenos estéticos nos quais desembocam tais fatos e os fenômenos morfológicos que manifestam essas instituições (MAUSS, 1974,p.41)
\end{abstract}

Todavia, o Fato Social Total não se constitui em total pela integração de aspectos aparentemente descontínuos como o familial, econômico, jurídico, religioso. É necessário que ele "se encarne em uma experiência individual e em um sistema de interpretação que simultaneamente considere os aspectos físico, fisiológico, psíquico e sociológico de todas as condutas². É perceptível o caráter tridimensional do Fato Social Total, uma vez que estabelece diálogo entre a dimensão sociológica

\footnotetext{
$\overline{1}$ LEVI-STRAUSS. Introdução à obra de Marcel Mauss, p.15. In: Sociologia e Antropologia II. São Paulo: Epu, 1974.

2 Cid.p. 14 
com seus aspectos sincrônicos, a dimensão diacrônica e a dimensão fisio-psicológica.

É a categoria Fato Social Total que permite ampliar a ligação entre o social e o individual para outras dimensões também necessárias para investigar a realidade social que é a aproximação do físico (ou fisiológico) e o psíquico. A complementariedade entre o psíquico e o social pensada por Mauss não pode ser percebida como algo estático. Longe disso. Ela é dinâmica "e provém de o psíquico ser ao mesmo tempo simples elemento de significação para um simbolismo que o ultrapassa, e o único meio de significação de uma realidade cujos aspectos múltiplos não podem ser apreendidos fora dele mesmo ${ }^{3}$.

No dom da dádiva, materializado na tríade dar, receber e retribuir, Mauss identifica o espírito da coisa, do(s) objeto(s) materiais ou simbólicos - o mana. É o mana como espírito, como força, fonte de energia que garante a circulação da dádiva.

Se coisas são dadas e retribuídas, é porque se dão e se retribuem
'respeitos' - podemos dizer igualmente, 'cortesias'. Mas é também as
pessoas se dão ao dar, e, se as pessoas se dão, é porque se 'devem'
- elas e seus bens- aos outros (MAUSS, 1974,p.63)

É através dele, desse espírito, que se confere aos implicados neste ritual performático, o elemento da honra, gentileza, prestígio, respeito, generosidade ou, no contrapondo, a desonra, a grosseria, o desprestígio, desrespeito e avareza. "O que no presente recebido e trocado, cria uma obrigação, é o fato de que a coisa recebida não é inerte. Mesmo abandonada pelo doador, ela ainda é algo dele"(MAUSS, 1974,p.54).

Neste caso, a dádiva para Mauss equivale a um crescimento da consciência do ser, uma vez que o ato de dar não é simplesmente oferecer algo de si, é, sobretudo, adquirir esse "si". O prestígio nasce da dádiva e relaciona-se àquele que toma a iniciativa: ao doador, para constituir seu próprio nome, sua fama, o valor de "renome"(MAUSS,1974,p.69).

Embora Mauss em seu Ensaio sobre a Dádiva tenha realizado seus estudos a partir de dados coletados em pesquisas etnográficas - produzidas por diferentes etnógrafos - nas chamadas sociedades "primitivas", a dádiva - no ato de dar, receber e retribuir - pode ser defendida como lógica organizativa do social de caráter universalizante, e que não pode ser reduzida somente a aspectos econômicos ou religiosos posto que, em todas as sociedades contidas na história da humanidade, é possível observar a presença de um sistema de reciprocidade. Assim, a obrigação do Dom da Dádiva aparece necessariamente como um fenômeno total, atravessando toda a vida social, uma vez que tudo que associa à vida humana - bens materiais ou simples gestos - tem relevância para a manutenção da sociedade. Eis aí o alcance conceitual da Dádiva (Karsenti, 1994).

No caso da encenação-quiasma, Oh de casa! Posso entrar para cuidar? as práticas dramatúrgicas do agradecer e do transformar - entrelaçando narrativas factuais e ficcionais, poesia, pensamentos, orações, cânticos etc - fazem das pequenas práticas vivenciadas pelas 10 (dez) atrizes-narradoras um ato dadivoso, porque

3 Op.Cid. p.15 
atua primeiro sobre cada uma, para depois atingir o outro. A exemplo, pequenos fragmentos de nossos roteiros dramatúrgicos recorrentes ao exercício de agradecer.

A atriz-narradora-éter dá a cada casa uma limpeza astral, varrendo, simbolicamente, todo o chão do aposento, acompanhada pelo cântico a seguir:

"Espiral, espiral, espiral, sugue o que há de ruim, leve todo o mal (2) Vou banindo pela terra e ar, vou banindo pelo fogo e mar Vou banindo, vou banindo, pra purificar Vou banindo, vou banindo, pra exterminar"

O ritual-cena faz uma pausa. A casa que recebe o teatro de cura e as atrizes-narradoras e os convidados recebem um ato de partilha de alimentos. Para todos são ofertadas, pelos moradores do lugar, comidas, bebidas e espaço de conversas sobre as sensações provocadas pelo ato cênico. Todos trocam experiências de vida, proposições e glorificações; um receber coletivizado com amor e cuidado.

É hora do retribuir. No teatro da cura há que se ter espaço para reencontros, reconciliações, reinício, recomeços, revivências... Relatamos a seguir, alguns momentos de retribuição mais sensíveis de nosso fazer artístico extraordinário.

Momento 1:

A atriz-narradora-fogo recebe no espetáculo a dádiva de contar sua história de vida: a grande gratidão que sentia e sente pelos seus falecidos avós. A atriz partilha com o público da casa muitos momentos vividos com os dois, hoje cultivados como antepassados na sua prática religiosa na Igreja Messiânica Mundial. Na sua narração, há um momento de partilha de compaixão, consigo e com os seus antepassados: a atriz narra aos espectadores-testemunhas o dia em que perdeu sua fiIha recém-nascida e teve que contar o acontecimento fatal aos bisavós da menina Maria. A atriz-fogo-mãe retribuiu todo o amor recebido, com um gesto de profunda gratidão : mesmo com sua profunda dor, teve forças para cuidar daqueles que amava, contando a eles a morte da filha Maria, não como perda de uma jovem vida, mas sim, como uma dádiva, que dê tão grande, teve duração tão pequena.

Para acompanhar tão dolorosa doação, a atriz-éter ampara o trabalho da atriz-fogo (Figura 1), com a música Não fala de Maria, de autoria de Chico Buarque.

\author{
Não fala de Maria \\ Maria lembra mar \\ Que lembra aquele dia \\ Que não é bom lembrar \\ Que dia, que tristeza \\ Que noite, que agonia \\ Que puxa a correnteza \\ E traz a maresia \\ E bate aquele vento \\ Que lembra um assobio \\ Que lembra um sofrimento \\ Que eu não merecia \\ Não fala não, te esconjuro
}


Que só de imaginar

O tempo fica escuro

E o espanto agita o mar

Que lembra aquele dia

Que lembra uma canção

Que faz lembrar Maria

E aí não lembro não

A coisa fica séria

É como um turbilhão

Fazendo uma miséria

No meu coração.

Figura 1. Atriz-narradora-fogo em cena, amparada pela atriz-éter.

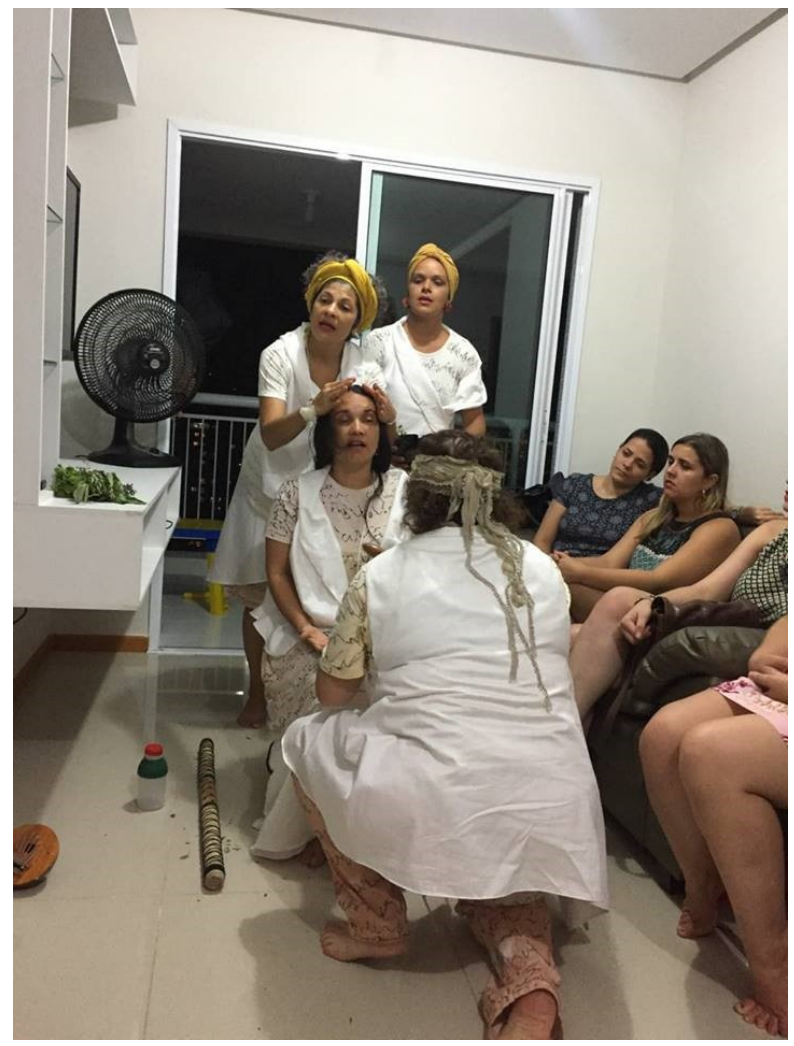

Fonte: Coletiva Xoxós.2016.

Momento 2:

A atriz-narradora-água partilha com os presentes na casa-útero o momento em que se torna mãe- de coração e alma - de um menino - que estava na casa de sua mãe. A atriz-narradora-água relata a emoção do primeiro encontro, da troca de olhares e do calor sentido quando do primeiro abraço trocado entre os dois. Risos, muitos risos vêem à tona, no relato emocionante da descoberta da maternidade. $\mathrm{A}$ narrativa singela ganha vida com a projeção de imagens do filho através do manuseio de um mini data show manuseado pela própria atriz e no cântico da música 
Onça Pintada, música de Zeca Baleiro apresentada à atriz-mãe por seu filho Pepeto;

Ê onça pintada,

Quem foi que te pintou?

Quem te pôs o preto,

Quem te pôs o preto,

Quem te amarelou [...]

Assim são os milagres do amar!

\section{O Teatro da Cura}

O teatro é o espaço por excelência da cena. É neste espaço - convencional ou não- que o ator ou um conjunto de atores interpretam papeis ligados a uma linguagem dramatúrgica cujo mote se assenta em despertar sentidos e sentimentos no público. O teatro como uma das dimensões da arte possui diferentes poéticas que dialogam com o público, ora no sentido de espanto, incômodo, desconforto, descobertas; ora no sentido da alegria, da libertação, do jubilo, do contado com o divino. Por possuir essas multiplicidades de nuances o teatro pode ser considerado dentre outras formas, como o espaço da crueldade de Antonin Artaud, como o teatro do Oprimido de Augusto Boal ou como instrumento instaurador na cultura dos vínculos proposto por Eugenio Barba e Nicole Savarese, como potência facilitadora do cuidado com o outro, como arte transformadora do sujeito e do mundo.

Neste artigo a lente usada para enxergar o teatro cola na dimensão proposta por teóricos da arte teatral contemporânea, sobretudo Barba, Savarese e Brook vinculados à Antropologia Teatral. A Antropologia Teatral é designada como "o estudo do comportamento cênico pré-expressivo que se encontra na base dos diferentes gêneros, estilos e papéis, e das tradições pessoais ou coletivas"(BARBA\&SAVARESE, 1995,p.8). Neste sentido o lugar de partida da Antropologia Teatral se localiza em um nível anterior à expressividade, lugar onde reside toda a base orgânica do trabalho do ator, do comportamento cênico, qual seja, o mundo das culturas, das memórias e dos afetos. Para Savarese, "o teatro não vale nada se não for construído sobre plataformas culturais, com essa hibridação. Ele é importante para refletir sobre a diversidade viva do mundo 4 .

É a poética do processo criativo do ator que estimula o olhar sensível desses teóricos da arte teatral contemporânea na medida em que desloca o teatro de uma concepção mais tradicional para outras dimensões onde pulsam estados de afetação entre ator e platéia, o teatro que busca tornar visível o invisível no exercício de resgate de seu caráter ritual, ou seja, o Teatro do Sagrado proposto por Peter Brook. Para ele

A qualidade reside no detalhe. A presença do ator, aquilo que dá qualidade ao seu ato de estudar ou de olhar, é uma coisa misteriosa, mas não indecifrável. Não é algo que esteja inteiramente acima de suas capacidades conscientes e voluntárias. Ele pode descobrir essa

\footnotetext{
${ }^{4}$ Fala de Savarese na conferência "O Oriente Teatral no Brasil", na Sede Roosevelt da SP Escola de Teatro Centro de Formação das Artes do Palco. Em 06/12/2012. In: http://www.spescoladeteatro.org.br/notícias acessado em 07/04/2016. 
presença num certo silêncio em seu íntimo. O que podemos denominar de "teatro sagrado", o teatro no qual o invisível aparece, tem por base esse silêncio, a partir do qual podem surgir todos os tipos de gestos, conhecidos e desconhecidos (BROOK, 1999,p.63).

É pertinente considerar que a base do Teatro Sagrado reside na crença da eficácia de uma linguagem simbólica. Neste caso, gestos, sons e palavras podem provocar transformações reais pela invocação através do símbolo usados como elementos de primeira grandeza no exercício cênico e na relação entre as energias. É a força do pensamento mágico-religioso, é o Dom da Dádiva defendido por Marcel Mauss que é transportado para o espaço da cena, atravessada por realidades simbólicas- das atrizes e da platéia - que se afetam e dialogam em constante estado de encantação numa comunhão de experiências.

No Teatro Sagrado Peter Brook quer mostrar que a experiência teatral está para além de uma sala com quatro paredes, cortinas vermelhas, palco fixo e lugares hierarquicamente preestabelecidos. Para este autor mais do que teatro, existe um ato teatral que nasce num espaço vazio que envolve um ator enquanto alguém o observa, envolvido, afetado pelo ato. Peter Brook no Teatro do Sagrado está preocupado com as relações submergidas ou perdidas, que atravessa os corpos com fluxos provenientes da criação, geradores de possibilidade de transição. "Cada vez que alguém rema de uma margem a outra, troca algo. Não cruza o rio para impor suas normas, mas para dar algo e receber algo em troca"(BARBA, 1991,p.104).

O teatro, que ora chamamos de teatro da cura, quer ir além do teatro como prática de autodescoberta e de compartilhamento. $\mathrm{O}$ teatro da cura quer, como seus procedimentos poéticos de atravessamentos, alterar os campos energéticos do corpo e do corpo-casa; quer através do uso das figuras de linguagem - o quiasma e a metáfora- irradiar vibrações que cuidem dos participantes do ato, sejam eles atuantes ou aqueles que o teatro ordinário chama de espectadores. $O$ teatro da cura quer atravessar corpos e paredes, quer religar dimensões e mundos, mesmo que em doses homeopáticas - doses homeopáticas de energia de cuidado, pertinentes e insistentes, a ponto de curar.

Nos pequenos fragmentos do roteiro dramatúrgico da encenação-quiasma Oh de Casa! Posso entrar para cuidar? particularmente agora voltados para o ato de transformar, as atrizes-narradoras, no encontro com seus elementais - terra, ar, água e fogo - desenvolvem uma espécie de retorno às reminiscências, no encontro consigo mesmas, identificando em suas biografias, histórias de vida que simbolizam atos de transformação em si e para si.

O corpo-casa se abre para receber cinco atrizes-narradoras. O elemento éter está à frente, seguido pelos elementos ar, fogo, água e terra. A entrada é marcada pela entoação -em capela- da música Divino (Rita Ribeiro/Zeca Baleiro):

\footnotetext{
Quase nunca vou à festa

Não vejo televisão

Não gosto de usar vermelho

Não me banho com loção

Não sei falar esperanto

Conversa fiada eu não...
} 
Quando durmo sonho, sonho

Quando acordo como pão.

São Judas, São Benedito;

São Cosme, cristinho meu.

A paixão é roupa velha que o

Rato da dor roeu, que o rato

Da dor roeu (2)

Na sequência a atriz-narradora-fogo inicia o ritual de dar, narrando uma história pessoal que mostra o processo de construção de vínculos afetivos entre mãe e filha. O relato atravessado de emoção descreve diferentes fases de sua vida em que ouviu da mãe a frase "um dia vais saber o que é ser mãe; um dia vais conhecer esse amor infinito...". A atriz narra o quanto zombava dessa frase, o quanto negava tudo que a ligasse ao mundo feminino marcado pela subserviência e passividade, o quanto negava aquele modelo de maternidade - marcado pela dedicação, atenção, amor, cuidado e zelo - que sua mãe representava. O momento da transformação acontece quando a atriz se descobre grávida de uma menina, de sua primeira filha e de perceber as mudanças físicas e emocionais que aconteciam em seu corpo, o corpo-abrigo de sua filha. A descoberta de um novo e incomensurável amor a aproxima de sua mãe. A transformação de seu corpo-abrigo em corpo-mãe materializado no cuidado zeloso para com sua filha fazendo-a exercitar a alteridade, esse sutil e delicado movimento que permite o Eu se deslocar de seu próprio eixo e ir ao encontro do outro, enxergando-se nesse outro. Durante toda a ação narrativa a atrizmãe modela nas mãos bolinhos de batata (Figura 2) que ao término são entregues aos presentes em um ato poético de partilha.

Figura 2. A atriz-narradora-fogo em cena, modelando bolinhos de batata no ato poético.

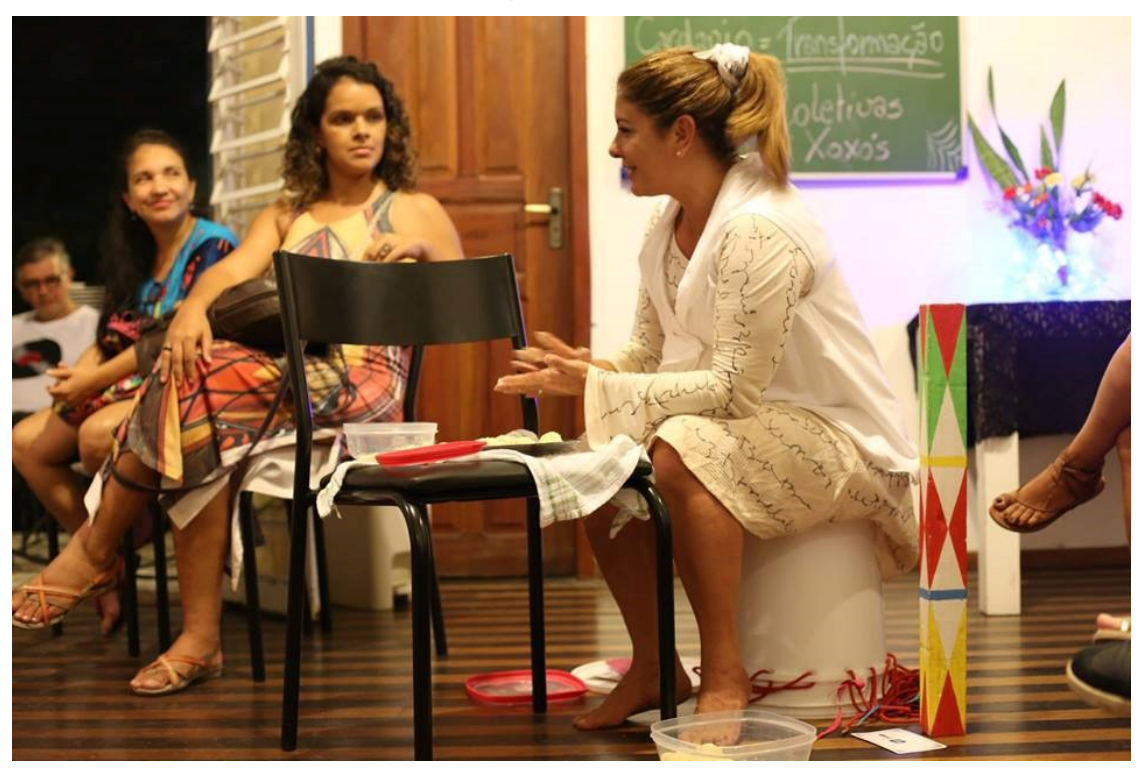

Fonte:coletiva Xoxós.2016 
Na sequência a atriz-ar canta em solo a música Cortei o Dedo de autoria de Carlos Carega/Raul Cruz.

\author{
Cortei o dedo \\ Quando você se foi \\ E ainda não sarou \\ Só quando você voltar meu amor \\ Aí eu paro de sangrar \\ Minha mãe falou \\ Não se assuste minha filha \\ Se na hora você sangrar \\ E eu não sangrei \\ E eu não sangrei \\ Antes da hora \\ E eu não sangrei \\ E eu não sangrei
}

A transformação é um ato de cura!

\title{
A Teoria da Dádiva e o Teatro da Cura, diálogos possíveis
}

O teatro da cura aqui composto tem inspiração nos teóricos Eugênio Barba, Savarese e Brook em diálogo com a teoria da dádiva de Marcel Mauss. O processo criativo do teatro da cura, mais especificamente no caso da encenação-quiasma Oh de casa! Posso entrar para cuidar? busca inspiração na metafísica do ser, na magia do sensível e na ecologia transcendente. Essa tríade que se constitui o pilar de inspiração filosófica na construção da encenação-quiasma propõe aproximações entre as dimensões do Ser- que está no mundo inteligível, no mundo concreto - e do Não-Ser- que transita no campo da fé e compreende as dimensões da alma humana.

A estrutura cênica da encenação-quiasma compreende três dimensões dialógicas: dar, receber e retribuir. Nessa tríade dimensional o mana - espírito das coisas - se faz presente. É o mana que funciona como um fio invisível e delicado, um campo de energia vibrátil que coloca atrizes e platéia na mesma sintonia. Esse espírito permite uma troca de sentimentos e afetos. Neste momento atrizes e platéia vivem o mesmo estado ritual - têm seus corpos mexidos, provocados, alterados.

No Ato de Dar, o projeto do Teatro da Cura através da encenação-quiasma oferece dois cardápios - um de transformação e outro de agradecimento- que deverá ser escolhido pelo corpo-casa acolhedor, considerando neste ato de escolha, o cardápio que melhor se adéqua à situação vivida pelos integrantes da família. Cada cardápio encenado é delicadamente construído a partir das memórias afetivas das atrizes e contam com pequenas histórias de vida, histórias ficcionais, poesias, pensamentos, cânticos, orações. Este último marcado pelo quiasma - jogo de palavras/jogo de linguagem. 
O Ato de receber é marcado pelo momento da encenação - do cardápio escolhido. É o momento ritual em que o corpo-casa recebe o presente performático. Em doses homeopáticas as energias emanadas das linguagens cênicas se deslocam por todos os espaços, provocando sensações e dilatando os sentidos das atrizes e da platéia. Neste momento, cada integrante da platéia - familiares e amigos - tendem a se tocar de forma extremamente particular com o dito e o não dito. É o momento que se pretende se constituir de uma catarse pessoal e subjetiva, no sutil exercício de retirada das grossas, densas e pesadas camadas de sentimentossensações absorvidas pela dura rotina do mundo moderno que impedem um encontro com o Eu verdadeiro. É neste momento que os procedimentos poéticos de atravessamentos buscam alterar os campos energéticos dos corpos no suave exercício de cuidado de si e do outro. Essa potente onda de entrelaçamento e troca energética é provocadora do encontro de alteridades, é provocadora do ato de curar.

O ato de Retribuir é o momento da comunhão. É o ritual da troca em que a casa-corpo partilha com os presentes qualquer tipo de alimento - preferencialmente feito por um dos integrantes da família. $\mathrm{O}$ ato de partilhar a comida, o alimento, é também o momento do congraçamento em que os participantes do ato poético trocam sensações, retornando aos corpos-atrizes suas identificações subjetivas com o cardápio apresentado. Os depoimentos colhidos, em sua maioria, retratam a identificação imediata por parte dos integrantes da platéia com as narrativas poéticas das atrizes. Não raro tais depoimentos são feitos em uma sintonia fina entre o riso e o choro. É o momento da alegria, da renovação. É o puro estado da delicadeza em que o abraço, o acolhimento, o sorriso e agradecimento, dão pistas de que o cuidado de si e do outro foram ativados.

Os atos, tanto de agradecimento quanto de transformação, se enceram em uma despedida ritualizada entre atrizes-narradoras, moradores-visitantes e a casamundo que os acolheu. As palavras performáticas de encerramento do ato são repetidas quantos forem os seus participantes multiplicados pelos cinco elementos da gira cênica: Eu te reconheço, eu te dou passagem e sigo o meu caminho! A saída das atrizes da casa é marcada pela música Despedida, de autoria de Antonio Nobrega;

Eu já estou de retirada,

É madrugada,

Dou lembranças aos senhores.

Sinto uma dor,

Dono da casa,

Até para o ano se eu vivo for.

Adeus, boa sorte para todos,

Eu já me vou.

Já vou me retirar.

Tenho saudades dessa noite tão bonita,

O meu coração palpita

Que eu não posso tolerar... 


\section{Referências}

BARBA, Eugenio; Além das Ilhas Flutuantes. trad. Luis Otávio Burnier, São Paulo - Campinas: Editora HUCITEC,1991.

BARBA, Eugenio; SAVARESE, Nicola. A arte secreta do ator. São Paulo/Campinas : Unicamp/Hucitec, 1995.

BROOK, Peter. O Teatro e seu espaço. Lisboa: Orfeu Negro, 2007.

KARSENTI, Bruno. Marcel Mauss. Le fait social total. Paris : PUF, 1994.

LÉVI-STRAUSS, Claude. Introdução. A obra de Marcel Mauss. In: Sociologia e Antropologia Volume II. São Paulo: EPU, 1974

MARTINS, Paulo Henrique. A Sociologia de Marcel Mauss: Dádiva, Simbolismo e Associação. In: Revista Crítica de Ciências Sociais [Online], 73/ 2005, colocado online no dia 01 de Outubro 2012, criado a 15 de julho 2015. URL:<http://rccs.revues.org/954> DOI: 10.4000/rccs.954

MAUSS, Marcel. Ensaio Sobre a Dádiva. Formas e Razão da Troca em Sociedades Arcaicas In: Sociologia e Antropologia Volume II. São Paulo: EPU, 1974.

Recebido em 29/08/2017 - Aprovado em 25/09/2017 